\title{
Wanna play? The role of self-construal when using gadgets to cope with ostracism
}

\author{
Michaela Pfundmair ${ }^{\mathrm{a} *}$, Friederike Eyssel ${ }^{\mathrm{b}}$, Verena Graupmann ${ }^{\mathrm{c}}$, Dieter Frey ${ }^{\mathrm{a}}$ and \\ Nilüfer Aydin ${ }^{\mathrm{d}}$ \\ ${ }^{a}$ Department of Psychology, Ludwig-Maximilians University of Munich, Munich, Germany; ${ }^{b}$ CITEC, \\ University of Bielefeld, Bielefeld, Germany; ${ }^{c}$ Department of Psychology, DePaul University, \\ Chicago, IL, USA; ${ }^{d}$ Institute of Psychology, Alpen-Adria University of Klagenfurt, \\ Klagenfurt, Austria
}

(Received 17 March 2015; accepted 13 July 2015)

\begin{abstract}
This research investigates how people with different self-construals benefit from social gadgets to cope with ostracism. The Pilot Study showed that an independent selfconstrual was associated with reports of less loneliness when using social surrogates. Studies 1 and 2 revealed that without access to a gadget, participants with independent self-construal showed more negative affect in response to ostracism compared to inclusion whereas participants with interdependent self-construal did not. When given access to gadgets like a social toy or a social robot, this difference diminished; participants with independent self-construal did not differ in their negative affect between ostracism and inclusion. These results suggest that social gadgets can serve as strategy for coping with ostracism, in particular, among people with an independent self-construal.
\end{abstract}

Keywords: ostracism; social surrogates; social gadgets; self-construal

Roughly two decades ago, technical gadgets like Tamagotchis or gameboys emerged as popular pastime for children and adolescents. Today, it is not surprising to observe groups of friends gathering while everyone is playing with a smartphone in the others' presence. While these phenomena are clearly related to the exponential technological development of our time, their psychological impact requires further analysis. Research has revealed that humans are fundamentally motivated by a need to belong (Baumeister \& Leary, 1995). Overcoming the highly aversive experience of ostracism, they use regulatory mechanisms, inter alia, social surrogates that are a "temporary stopgap for our social hunger" (Gardner, Pickett, \& Knowles, 2005, p. 232). In the present research, we examined whether also technological gadgets can serve as social surrogates to cope with ostracism. As coping with ostracism is facilitated for people with an interdependent self-construal (Gardner, Knowles, \& Jefferis, in prep; Pfundmair, Graupmann, Frey, \& Aydin, 2015; Ren, Wesselmann, \& Williams, 2013), we particularly aimed to investigate how self-construal related differences impact the use of social gadgets in coping with ostracism.

\section{Ostracism and social surrogates}

Early on in evolution, ostracism from one's group could be likened to a "death sentence," as survival without the protection of a group was highly unlikely (Gruter \& Masters,

*Corresponding author. Email: michaela.pfundmair@psy.lmu.de 
1986). Accordingly, it has been proposed that humans have developed a monitoring system that reacts to cues of ostracism: After the physical pain which follows ostracism (Eisenberger, Lieberman, \& Williams, 2003), individuals are mentally alarmed by a decrease of basic psychological needs satisfaction and mood (Williams, 2009).

Recent research has shown that people rely on strategies to alleviate social pain-for instance, ostracized individuals use photos of loved ones (Gardner et al., 2005), watch favored television shows (Derrick, Gabriel, \& Hugenberg, 2009), or eat comfort food (Troisi \& Gabriel, 2011) to remind themselves of social relationships. The strategy of using representational reminders of real social bonds provides a temporary substitute for direct interaction. Any object has the potential to be a social surrogate if it is related to feelings of affiliation (Troisi \& Gabriel, 2011). Why should an object like a gadget have the power to alleviate the psychological pain of ostracism? People tend to perceive humanlike characteristics in nonhuman agents, thereby anthropomorphizing them (Epley, Waytz, Akalis, \& Cacioppo, 2008; Epley, Waytz, \& Cacioppo, 2007). Thus, although people need other humans in daily life to assure psychological well-being, under specific circumstances, they even form bonds with nonhumans. These bonds might be especially relevant for coping efforts in the face of ostracism-in particular among those people who are less successful in coping with ostracism due to their kind of self-construal.

\section{Ostracism and self-construal}

The self can be distinguished into independent and interdependent aspects: People with independent self-construal value individual uniqueness and personal autonomy; their primary goal is to set themselves apart from others in a positive manner. People with interdependent self-construal, on the other hand, define themselves mainly by means of interpersonal relations; social representations are chronically accessible (Heine, Lehman, Markus, \& Kitayama, 1999).

Independent and interdependent self-construals (and likewise, their cultural correlates, the dimensions of individualism and collectivism; Hofstede, 1980) are differentially related to the experience of ostracism: Compared to independently defined individuals, people with interdependent self-construal report less negative mood and higher selfesteem (Gardner et al., in prep), show less antisocial behavioral intentions (Pfundmair et al., 2015), and recover quicker from ostracism (Ren et al., 2013). This "internal advantage" in dealing with ostracism has been explained by their chronically accessible social representations actively buffering them (Gardner et al., in prep) and by ostracism being experienced as less of a threat (Pfundmair et al., 2015). Ostracized people with an independent self-construal, on the other hand, are comparably more vulnerable and therefore exposed to ostracism somewhat unprotected.

It has been shown that exposure to a social surrogate increases the activation of the collective self (Valenti, Gabriel, \& Young, 2012). Therefore, using social surrogates might be an appropriate, external technique to cope with ostracism, especially for people who lack a more collective (interdependent) self-construal. Thus, we suppose that gadgets can facilitate coping with ostracism among independently defined people.

\section{Overview of the present research}

The present studies examined the psychological benefits of social gadgets in coping with ostracism among participants with independent versus interdependent self-construals. 
In a preliminary correlational study, we looked at the relationship between self-construal and feelings of loneliness when engaging in social surrogacy activities. In the two main studies, we experimentally manipulated ostracism by the virtual ball-tossing game Cyberball and operationalized social surrogacy using a social toy, i.e., a smartphone application (Study 1) and a toy robot (Study 2). To capture the superficiality of social surrogates being only a temporary stopgap for social hunger (Gardner et al., 2005), we investigated affect measures that have been shown to work on a rather short-term level in contrast to the long-term effective basic needs measure (basic needs but not mood mediate effects of ostracism; see meta-analysis by Gerber \& Wheeler, 2009). We hypothesized that the use of social surrogates to cope with negative consequences of ostracism would be contingent on a person's social self-definition, with these with independent self-construal benefiting more from social surrogates than those with interdependent self-construal.

\section{Pilot Study}

In the Pilot Study, we explored the relationship between loneliness during the use of social surrogates and self-construal.

\section{Method}

Participants and procedure

Eighty-eight German undergraduate students (60 women, 28 men, age: $M=23.03$, $\mathrm{SD}=6.55)$ participated in this study for research credit.

Participants completed a questionnaire measuring self-construal and feelings of loneliness during various activities, followed by a debriefing.

\section{Materials}

\section{Self-construal}

Participants responded to 32 statements assessing horizontal and vertical individualism and collectivism (Singelis, Triandis, Bhawuk, \& Gelfand, 1995) on 1 (not at all) to 7 (very тисh) scales. We cumulated the horizontal and vertical individualism (e.g., "Winning is everything"; $\alpha=.82$ ) and collectivism items (e.g., "My happiness depends very much on the happiness of those around me"; $\alpha=.79$ ) and calculated a difference score by deducting the mean score of collectivism from that of individualism ${ }^{1}$. Accordingly, higher values reflect an independent self-construal and lower values an interdependent selfconstrual.

\section{Activities}

Adapted from Derrick et al. (2009), participants indicated how likely they would feel lonely when engaging in 10 various activities on a scale ranging from 1 (not lonely at all) to 7 (very lonely). The activities were either social surrogacy activities, i.e., associated with feelings of belonging (watching one's favorite movie, listening to one's favorite music, and surfing the web; $\alpha=.59$ ), or other activities (renting a new movie, listening to any music on the radio, eating, focussing on work, exercising, cleaning the room, and going for a walk/biking/jogging; $\alpha=.79$ ). 


\section{Results and discussion}

To examine how strongly an independent self-construal is associated with feelings of loneliness when using social surrogates, we calculated correlations between self-construal and self-reported loneliness during the chosen activities. We observed a significant correlation only with regard to social surrogacy activities: The more independently defined, the less people felt lonely when they engaged in them, $r(88)=-.30, p=.004$. There was no significant correlation between self-construal and feelings of loneliness during the other activities, $r(88)=-.09, p=.385$

These findings provide an initial hint that people with independent self-construal who are more affected by ostracism (Gardner et al., in prep; Pfundmair et al., 2015; Ren et al., 2013) benefit more from social surrogacy activities when ostracized. However, because of the correlational nature of our findings, conclusions can only be drawn with caution. To examine the causal relationship, we conducted two experiments using real-time ostracism and interactive social surrogates.

\section{Study 1}

In Study 1, we conducted an experiment to investigate directly whether a social gadget would enhance coping with ostracism among individuals with independent (versus interdependent) self-construal. We manipulated exclusionary status through Cyberball, a virtual ball-tossing game, and operationalized social surrogacy by providing a real "social toy," a smartphone application. To investigate superficial vs. long-term effective coping, we measured affect in contrast to basic needs. We hypothesized the following: (1) Participants with interdependent self-construal would be less strongly affected by ostracism than participants with independent self-construal under "normal" conditions (i.e., in the no-gadget control condition). (2) Coping efforts of participants with independent self-construal would be less negatively affected by ostracism when supported, rather than unsupported, by a gadget, whereas participants with interdependent selfconstrual would not differentiate between gadget and no-gadget conditions.

\section{Method}

\section{Participants and design}

Fifty-nine German students (47 women, 12 men, age: $M=24.12$, SD = 8.41) participated in this study for research credit.

Participants were randomly assigned to a 2 (exclusionary status: ostracism vs. inclusion) $\times 2$ (surrogate: gadget vs. no-gadget) between-subject design; self-construal served as continuous moderator variable.

\section{Procedure}

Participants were recruited to participate in a study on game playing behavior including new technologies. After answering filler questions and items on self-construal, participants were introduced to the smartphone app "Gina," a digital giraffe. Participants were invited to play with it for a few minutes in order to facilitate feelings of affiliation, a necessary precondition for a social surrogate to be effective (Troisi \& Gabriel, 2011). After this brief interaction, participants played Cyberball. Importantly, then, participants in the gadget condition had the opportunity to engage in an interaction with "Gina" while completing the remaining part of the questionnaire including items on affect, need fulfillment and 
manipulation checks; they could freely decide how long they interacted with it. In the nogadget condition, "Gina" was taken away. In the end, they were thanked and debriefed.

\section{Materials}

\section{Self-construal}

As in the Pilot Study, we computed a difference score based on participants' responses to Singelis' et al. (1995) horizontal and vertical individualism $(\alpha=.85)$ and collectivism items $(\alpha=.80)$. For a detailed examination, values were predicted at percentiles of this score.

\section{Exclusionary status}

The virtual ball tossing game "Cyberball" (Williams \& Jarvis, 2006) was used to manipulate exclusionary status: Participants were led to believe that they were playing with two other participants in a computer network. A computerized ball was tossed 40 times between them. Participants were thrown the ball roughly one third of the time by the other "players" (inclusion condition) or they were passed the ball twice at the beginning of the game and never again (ostracism condition).

\section{Social surrogate}

We introduced participants to the smartphone app "Gina." Participants learned that they could feed and play with the giraffe and "Gina" imitated participants' verbal reaction. After manipulating exclusionary status, participants either had access to "Gina" (gadget condition) or not (no-gadget condition).

\section{Affect}

Participants were asked to fill out the 20-item Positive and Negative Affect Schedule (PANAS; Watson, Clark, \& Tellegen, 1988) on 1 (not at all) to 5 (very much) scales. To account for PA and NA being distinct constructs (Watson, Wiese, Vaidya, \& Tellegen, 1999), we separately aggregated the positive (e.g., "active"; $\alpha=.84$ ) and negative affect items (e.g., "distressed"; $\alpha=.87$ ).

\section{Need fulfillment}

Participants responded to 12 items assessing the fulfillment of belonging, self-esteem, control, and meaningful existence (e.g., "I felt good about myself"; Zadro, Williams, \& Richardson, 2004); responses were averaged $(\alpha=.88)$.

\section{Manipulation checks}

Assessing the success of Cyberball, participants answered two items ("What percent of the throws were thrown to you?", "To what extent were you excluded by the other participants during the game?"; Zadro et al., 2004). Moreover, participants in the gadget condition reported the time they spent with "Gina" during completion of the final questionnaire.

Except stated otherwise, all items were rated on 1 (not at all) to 9 (very much) scales. 


\section{Results}

\section{Preliminary analyses}

Participants in the ostracism condition reported having received significantly fewer ball passes $(M=5.33, \mathrm{SD}=3.27)$ than participants in the inclusion condition $(M=34.57$, $\mathrm{SD}=13.02), t(57)=11.74, p<.001, d=-3.11$. Moreover, ostracized participants reported feeling significantly more excluded $(M=8.52, S D=0.63)$ than included ones $(M=3.37, S D=2.43), t(57)=-11.06, p<.001, d=-2.93$. Participants who had access to "Gina" during the final phase of the study reported to have interacted with it significantly longer than zero minutes $(M=1.00, S D=1.54), t(29)=3.56, p=.001$, $d=1.32$.

\section{Interplay of exclusionary status and self-construal}

To examine the impact of ostracism versus inclusion on participants with independent and interdependent self-construals when not having access to the gadget, we conducted moderation analyses for the no-gadget condition. We used Hayes (2013) PROCESS tool entering exclusionary status (dummy coded as $-1=$ ostracism and $1=$ inclusion) as independent variable, self-construal as moderator, and affect and need fulfillment as dependent variables.

The moderation model on positive affect indicated neither a significant main effect of exclusionary status, $b=-0.09, \mathrm{SE}=.17, t(25)=-0.53, p=.600$, nor an interaction effect, $b=-0.08, \mathrm{SE}=.14, t(25)=-0.61, p=.549$.

For negative affect, a significant main effect of exclusionary status, $b=-0.32$, $\mathrm{SE}=.10, t(25)=-3.38, p=.002$, and of self-construal emerged, $b=0.23, \mathrm{SE}=.08$, $t(25)=2.95, p=.007$, indicating more negative affect following ostracism compared to inclusion and among participants with independent self-construal compared to participants with interdependent self-construal. Importantly, the analysis also revealed a marginal significant interaction effect, $b=-0.15, \mathrm{SE}=.08, t(25)=-1.94, p=.064$. In probing this interaction, we observed that those high in independence (90th percentile), $b=-0.34, \mathrm{SE}=.10, t(25)=-3.34, p=.003$, those moderately high in independence (75th percentile), $b=-0.28, \mathrm{SE}=.08, t(25)=-3.42, p=.002$, and those with a mixed self-construal (50th percentile), $b=-0.22, \mathrm{SE}=.07, t(25)=-3.08, p=.005$, indicated more negative affect when ostracized than when included. On the other hand, those high in interdependence (10th percentile), $b=0.02, S E=.13, t(25)=0.12$, $p=.906$, and those moderately high in interdependence (25th percentile), $b=-0.05$, $\mathrm{SE}=.10, t(25)=-0.51, p=.612$, did not differ between conditions.

For need fulfillment, a significant main effect of exclusionary status emerged, $b=1.00, \mathrm{SE}=.22, t(25)=4.61, p<.001$ : Ostracized participants indicated lower need fulfillment than included participants. There was no significant interaction effect, $b=-0.18, \mathrm{SE}=.18, t(25)=-1.00, p=.328$.

\section{Interplay of exclusionary status, surrogate, and self-construal}

To investigate how participants with independent and interdependent self-construals differentially coped with ostracism when playing with "Gina," we conducted multiple moderation analyses using the PROCESS tool by Hayes (2013). We entered exclusionary status (dummy coded as $-1=$ ostracism and $1=$ inclusion) and surrogate (dummy coded as $-1=$ no-gadget and $1=$ gadget) as independent variables, and self-construal as moderator; as dependent variables, we entered affect and need fulfillment. 
For positive affect, the moderation model only showed a marginally significant main effect of exclusionary status, $b=-0.17, \mathrm{SE}=.10, t(51)=-1.75, p=.086$. No significant three-way interaction emerged, $b=0.01, \mathrm{SE}=.07, t(51)=0.17, p=.868$.

For negative affect, a significant main effect of exclusionary status emerged, $b=-0.22, \mathrm{SE}=.08, t(51)=-2.85, p=.006$. The moderation model also revealed a significant surrogate $\times$ self-construal interaction, $b=-0.15, \mathrm{SE}=.06, t(51)=-2.53$, $p=.015$, and, importantly, a significant three-way interaction, $b=0.13, \mathrm{SE}=.06, t$ $(51)=2.15, p=.037$, see Figure 1 . To probe this interaction, we analyzed the conditional effect of exclusionary status $x$ surrogate at different values of the moderator: The conditional effect was marginally significant among those high in independence (90th percentile), $b=0.21, \mathrm{SE}=.12, t(51)=1.83, p=.073$, and among those high in interdependence (10th percentile), $b=0.21, \mathrm{SE}=.12, t(51)=1.80, p=.079$ : With no access to "Gina," highly independent participants reported more negative affect after ostracism than after inclusion, $b=-0.46, \mathrm{SE}=.19, t(51)=-2.35, p=.023$, but with access to "Gina" they did not differ between ostracism and inclusion, $b=-0.03$, $S E=.12, t(51)=-0.27, p=.785$. On the other hand, highly interdependent participants did not differ between ostracism and inclusion when not supported by "Gina," $b=0.06$, $\mathrm{SE}=.19, t(51)=0.33, p=.744$, but when supported, indicated more negative affect after ostracism than after inclusion, $b=-0.36, \mathrm{SE}=.14, t(51)=-2.63, p=.011$.

For need fulfillment, a significant main effect of exclusionary status, $b=1.19$, $\mathrm{SE}=.16, t(51)=7.45, p<.001$, a marginally significant main effect of surrogate, $b=0.28, \mathrm{SE}=.16, t(51)=1.76, p=.085$, and a marginally significant surrogate $\times$ selfconstrual interaction emerged, $b=0.20, \mathrm{SE}=.12, t(51)=1.68, p=.098$. There was no significant three-way interaction, $b=0.05, \mathrm{SE}=.12, t(51)=0.42, p=.679$.

\section{Discussion}

Study 1 showed that among participants with higher independent self-construal, a social gadget represented an effective coping tool when facing ostracism: Without access to "Gina," they indicated more negative affect in response to ostracism than to inclusion; with access to "Gina," they did not differ between conditions. As people with independent self-construal are more affected by ostracism (Gardner et al., in prep; Pfundmair et al., 2015; Ren et al., 2013), they might have to rely on external strategies like social surrogates to cope with ostracism. In Study 2, we aimed to replicate and extent these findings.

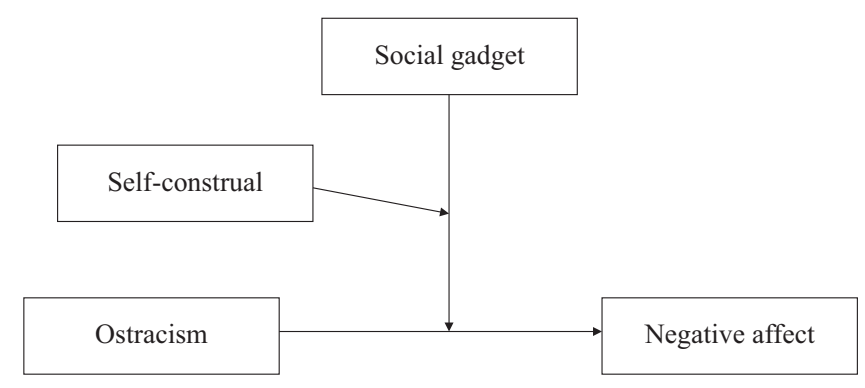

Figure 1. Conditional effect of exclusionary status on negative affect (Studies 1 and 2): Without access to a social gadget, participants with independent self-construal indicated more negative affect in response to ostracism than to inclusion; when given access to a social gadget, their negative affect did not differ between inclusion and ostracism. 


\section{Study 2}

Our previous work suggested that an independent self-construal is associated with reduced feelings of loneliness and facilitated coping with ostracism when supported by a social surrogate. The aim of Study 2 was to replicate these findings using a more appealing and tangible gadget as surrogate. We therefore provided participants with a social robot, the dinosaur "Pleo." Exclusionary status was once again manipulated via Cyberball. To investigate an emotional reaction directly adapted to the Cyberball experience, participants responded to affect variables validated by Zadro et al. (2004) before answering items on need fulfillment. Moreover, we asked for the participants' desire to spend time with the gadget to further explore the gadget's function as psychological substitute. We expected 1) participants with interdependent self-construal to be less strongly affected by ostracism than participants with independent self-construal in the nogadget condition. Further, we hypothesized that 2) coping efforts of participants with independent self-construal would be less negatively affected by ostracism when supported, rather than unsupported by a gadget, whereas participants with interdependent self-construal would not differentiate between gadget and no-gadget conditions. Finally, we expected that 3) an independent self-construal would be associated with an increased desire for the gadget after ostracism and interacting with the gadget.

\section{Method}

\section{Participants and design}

Eighty students from a German university participated in this study for research credit or a small reimbursement. Participants who had technical difficulties during the experiment $(N=3)$ and non-native German speakers $(N=9)$ were excluded, leaving us with a final sample of 68 participants (32 female, 36 male, age: $M=23.89, \mathrm{SD}=6.52$ ).

They were randomly assigned to a 2 (exclusionary status: ostracism vs. inclusion) $\times 2$ (surrogate: gadget vs. no-gadget) between-subject design; self-construal served as continuous moderator variable.

\section{Procedure}

The procedure was nearly identical to Study 1. However, in Study 2, we used the zoomorphic robot "Pleo," and instead of the PANAS measure, participants responded to affect items adapted to their Cyberball experience. Moreover, they indicated their desire to spend time with "Pleo." As part of a larger research project, participants also completed items on anthropomorphism that are not included in this paper.

\section{Materials}

\section{Self-construal}

As in the previous two studies, participants completed Singelis et al. (1995) horizontal and vertical individualism $(\alpha=.79)$ and collectivism scale $(\alpha=.81)$; again, we calculated the difference score.

\section{Exclusionary status}

We used Cyberball with identical settings as in Study 1. 


\section{Social surrogate}

We introduced the zoomorphic pet robot "Pleo" to the participants using the same script as in Study 1. "Pleo" emulates the appearance of a baby Camarasaurus and reacts to touch with various behaviors. After manipulating exclusionary status, participants were either given the opportunity to further play with "Pleo" or it was removed.

\section{Affect}

Participants answered two single items with positive and negative valence ("I enjoyed playing the Cyberball game", "I felt angry during the Cyberball game"; Zadro et al., 2004).

\section{Need fulfillment}

As in Study 1, participants responded to 12 items assessing their need fulfillment which were aggregated $(\alpha=.90)$.

\section{Desire to spend time with gadget}

Participants completed two items assessing their desire to spend time with "Pleo" ("How much would you like to have Pleo at home?", "Imagine Pleo was yours. How much time would you spend with Pleo?"); the items were separately answered on a continuous scale and an open field.

\section{Manipulation checks}

The success of both manipulations was evaluated as in Study 1.

All items were rated on 1 (not at all) to 9 (very much) scales.

\section{Results}

\section{Preliminary analyses}

Participants in the ostracism condition reported having received significantly fewer throws $(M=5.43, \mathrm{SD}=3.24)$ than participants in the inclusion condition $(M=35.66$, $\mathrm{SD}=11.98), t(66)=14.20, p<.001, d=3.50$. Likewise, they felt significantly more excluded $(M=8.29, \mathrm{SD}=1.17)$ than participants in the inclusion condition $(M=3.68$, $\mathrm{SD}=2.08), t(66)=-11.27, p<.001, d=-2.77$. Participants with access to "Pleo" during the last part of the questionnaire reported interactions to be significantly longer than zero minutes $(M=3.15, \mathrm{SD}=2.94), t(33)=6.24, p<.001, d=2.17$.

\section{Interplay of exclusionary status and self-construal}

To examine the impact of ostracism versus inclusion on participants with independent and interdependent self-construals when not having access to the gadget, we conducted moderation analyses for the no-gadget condition. Again, we used Hayes (2013) PROCESS tool entering exclusionary status (dummy coded as $-1=$ ostracism and $1=$ inclusion) as independent variable, self-construal as moderator, and affect and need fulfillment as dependent variables.

The moderation model on the positive affect item only revealed a significant main effect of exclusionary status, $b=1.00, \mathrm{SE}=.43, t(29)=2.31, p=.028$, with ostracized 
participants indicating less enjoyment in response to Cyberball than included participants. No significant interaction emerged, $b=0.32, \mathrm{SE}=.30, t(29)=1.06, p=.298$.

For the negative affect item, a significant main effect of exclusionary status, $b=-1.11, \mathrm{SE}=.38, t(29)=-2.88, p=.007$, and a marginally significant main effect of self-construal emerged, $b=0.52, \mathrm{SE}=.27, t(29)=1.95, p=.061$ : Ostracized compared to included participants and participants with independent self-construal compared to participants with interdependent self-construal indicated more anger in response to Cyberball. Moreover, the moderation model demonstrated a marginally significant interaction, $b=-0.51, S E=.27, t(29)=-1.90, p=.068$. As in Study 1 , those high in independence (90th percentile), $b=-1.27, \mathrm{SE}=.44, t(29)=-2.91$, $p=.007$, those moderately high in independence ( 75 th percentile), $b=-1.08, \mathrm{SE}=.38$, $t(29)=-2.87, p=.008$, and those with a mixed self-construal (50th percentile), $b=-0.63, \mathrm{SE}=.32, t(29)=-1.96, p=.060$, indicated more anger following ostracism than inclusion. On the other hand, those high in interdependence (10th percentile), $b=0.03, \mathrm{SE}=.51, t(29)=0.06, p=.953$, and those moderately high in interdependence ( 25 th percentile), $b=-0.29, \mathrm{SE}=.39, t(29)=-0.73, p=.470$, did not differ in their anger level between conditions.

For need fulfillment, a significant main effect of exclusionary status emerged, $b=1.35, \mathrm{SE}=.29, t(29)=4.61, p<.001$, with ostracized participants indicating lower need fulfillment than included participants. There was no significant interaction, $b=0.07$, $\mathrm{SE}=.20, t(29)=0.34, p=.738$.

\section{Interplay of exclusionary status, surrogate, and self-construal}

To investigate how participants with independent and interdependent self-construals coped with ostracism in dependence of having access to "Pleo," we conducted multiple moderation analyses using the PROCESS tool by Hayes (2013). We entered exclusionary status (dummy coded as $-1=$ ostracism and $1=$ inclusion) and surrogate (dummy coded as $-1=$ no-gadget and $1=$ gadget) as independent variables, and self-construal as moderator; affect and need fulfillment served as dependent variables.

For the positive affect item, a significant main effect of exclusionary status, $b=0.85$, $\mathrm{SE}=.28, t(60)=2.99, p=.004$, but no significant three-way interaction emerged, $b=-0.23, \mathrm{SE}=.19, t(60)=-1.21, p=.233$.

For the negative affect item, both the main effect of exclusionary status, $b=-0.77$, $\mathrm{SE}=.27, t(60)=-2.84, p=.006$, and the main effect of self-construal were marginally significant, $b=0.34, \mathrm{SE}=.19, t(60)=1.84, p=.071$. Moreover, the moderation model revealed a marginally significant three-way interaction, $b=0.36, \mathrm{SE}=.19, t(60)=1.95$, $p=.056$, see Figure 1. To probe this interaction, we analyzed the conditional effect of exclusionary status $\times$ surrogate at different values of the moderator. The conditional effect was marginally significant among those high in independence (90th percentile), $b=0.70$, $\mathrm{SE}=.40, t(60)=1.72, p=.090$ : whereas highly independent participants indicated more anger after ostracism than after inclusion when not supported by "Pleo," $b=-1.62$, $\mathrm{SE}=.59, t(60)=-2.76, p=.008$, they did not differ between inclusion and ostracism when supported by "Pleo," $b=-0.22, \mathrm{SE}=.56, t(60)=-0.39, p=.696$. On the other hand, there was no significant conditional effect of exclusionary status $x$ surrogate among those high in interdependence (10th percentile), $b=-0.51, \mathrm{SE}=.37, t(60)=-1.38, p=.173{ }^{2}$

For need fulfillment, there was only a significant main effect of exclusionary status, $b=1.26, \mathrm{SE}=.19, t(60)=6.52, p<.001$. No significant three-way interaction emerged, $b=0.04, \mathrm{SE}=.13, t(60)=0.28, p=.779$. 


\section{Desire to spend time with gadget}

The same multiple moderation analysis as defined in the section above revealed a significant three-way interaction on the item on how much participants wanted to have "Pleo" at home, $b=-0.40, \mathrm{SE}=.19, t(60)=-2.06, p=.044$. Among those high in interdependence (10th percentile), a marginal significant conditional effect of exclusionary status $\times$ surrogate emerged, $b=0.67, \mathrm{SE}=.38, t(60)=1.77, p=.083$ : Whereas highly interdependent participants did not differ between ostracism and inclusion when not supported by "Pleo," $b=-0.14, \mathrm{SE}=.54, t(60)=-0.26, p=.798$, they indicated a greater desire for "Pleo" in response to inclusion compared to ostracism, $b=1.19, S E=.52, t(60)=2.27, p=.027$. For the item on how much time they wanted to spend with "Pleo," a marginal significant surrogate $\mathrm{x}$ self-construal interaction, $b=4.84, S E=2.83, t(51)=1.71, p=.093$, but no three-way interaction emerged, $b=-3.66, \mathrm{SE}=2.83, t(51)=-1.30, p=.201$.

To map on to the analyses of the Pilot Study, we moreover calculated correlations on the participants' desire to spend time with "Pleo" and self-construal. We analyzed these separately for each of the four conditions. Results revealed significant correlations only for the ostracism condition with access to "Pleo:" The more independently defined participants were, the more they wanted to have "Pleo" at home, $r(17)=.51, p=.035$, and the more time they wanted to spend with "Pleo," $r(15)=.52, p=.048$. There were no significant correlations for the ostracism/no-gadget condition, $p s>.234$, the inclusion/ gadget condition, $p s>.157$, or the inclusion/no-gadget condition, $p \mathrm{~s}>.289$.

\section{Discussion}

Study 2 replicated and extended Study 1 in that the zoomorphic robot "Pleo" facilitated coping with ostracism among participants with independent self-construal: Without access to the social gadget, they reported more anger after ostracism than after inclusion-this difference diminished when given access to "Pleo." However, with the aim of using Cyberball-specific and validated variables, the participants' emotional reaction was only captured by two single items which reduces the robustness of the effect. We moreover observed that an independent self-construal was associated more strongly with the desire to spend time with the robot "Pleo" when ostracized and given access to the gadget.

\section{General discussion}

The current work provides empirical evidence that social gadgets can help to cope with ostracism, however, the extent of this support is dependent on self-construal. The Pilot Study revealed that an independent self-construal was associated with lower feelings of loneliness when using social surrogates. In Studies 1 and 2, participants with independent self-construal reported more negative affect in response to ostracism compared to inclusion without access to a social gadget; importantly, this difference diminished when given access to a gadget. Our gadgets only proved effective with respect to affect but not need fulfillment, thus remaining on a rather superficial psychological level and pointing to the surrogate's characteristic as “temporary stopgap for our social hunger" (Gardner et al., 2005 , p. 232). Therefore, it might be concluded that social gadgets can be useful for shortterm emotion regulation but do not appropriately compensate negative consequences in the long-term. Nevertheless, the results suggest that not only surrogates like pets (McConnell, Brown, Shoda, Stayton, \& Martin, 2011) or plants (Knowles, Liu, \& 
Sassaman, 2015) but also social gadgets have the power to conditionally facilitate coping with ostracism.

The current findings also add to the evidence of an independent self-construal being characterized by more psychological susceptibility to ostracism (Gardner et al., in prep; Pfundmair et al., 2015; Ren et al., 2013). While persons with an interdependent selfconstrual seem to be less threatened by ostracism, it is, on the other hand, plausible that individuals with an independent self-construal may feel the need to make use of external social strategies to cope with negative consequences of ostracism. Since social surrogates seem to activate the collective self (Valenti et al., 2012), the use of social surrogates might represent an appropriate technique for an independent self to compensate for its deficit and cope with ostracism.

As people with interdependent self-construals are less vulnerable to negative consequences of ostracism when not having access to a social surrogate, we concluded that they do not make use of social surrogates to cope with ostracism. However, it is also possible that they use external resources to cope with ostracism if such resources are available; if not, they might rely on their internal cognitive resources which people with independent self-construal poorly do. Interestingly, in this regard, is the result pattern of Study 1 and trending of Study 2. Here, participants with interdependent self-construal displayed more negative affect after ostracism when supported by the gadget in contrast to when not supported. Moreover, in Study 2 their desire for the gadget was more pronounced in the inclusion than in the ostracism condition. This might have been either caused by poorer (external) coping performances when internal coping is "turned off;" or by a distraction of their "normal" internal coping behavior through the external resources.

\section{Limitations and future directions}

Our findings indicate that turning to technical gadgets can function as a coping strategy in response to ostracism, in particular, among people with independent self-construal. We concluded that those individuals would compensate for their lack of strong social ties implied in social networks; however, we did not explicitly investigate this assumption. It might also be that people with independent self-construal experienced the gadget as a simple distraction from ostracism (distraction expedites recovery from ostracism; Wesselmann, Ren, Swim, \& Williams, 2013). This alternative approach should be examined in future studies.

Some methodological limitations should also be addressed. First, we are well aware of the fact that our studies yielded mainly small effects which might be due to the relatively small sample sizes. Second, it should be considered that participants in the ostracism/nogadget conditions had to face two ostracizing experiences-one during Cyberball and the other during the gadget's removal-which could eventually have prolonged the distress. However, as the no-gadget condition did not always contrast negatively against the gadget condition (only among participants with independent but not interdependent selfconstrual), we suggest that this double-ostracism did not affect our results. Third, it should be noted that although all participants had a small time delay between playing Cyberball and finishing the questionnaire (caused by removing the gadget before completing the questionnaire in the no-gadget conditions or playing with the gadget during completing the questionnaire in the gadget conditions), this time delay was bigger for participants in the gadget (Study 1: on average 1 minute; Study 2: on average 3.15 minutes) than in the no-gadget conditions (Studies 1 and 2: on average 0.5 minutes). In a recent meta-analysis, it has been shown that the time passed after an ostracism episode is likely to affect the 
extent of immediate distress (Hartgerink, van Beest, Wicherts, \& Williams, 2015). However, as the recovery time difference did not have a general positive impact (only participants with independent but not interdependent self-construal benefited from the gadget conditions), we assume that the temporal difference did not confound our results.

\section{Conclusion}

The current studies revealed that access to social gadgets can serve as strategy for coping with ostracism - particularly among people with a more independent self-construal. Thus, being independently defined it seems reasonable to seek support by social technology in the face of ostracism.

\section{Funding}

This research was partly supported by the Cluster of Excellence Cognitive Interaction Technology 'CITEC' (EXC 277) at Bielefeld University, which is funded by the German Research Foundation (DFG).

\section{Disclosure statement}

No potential conflict of interest was reported by the authors.

\section{Notes}

1 There is some debate on whether individualism and collectivism represent two independent dimensions or rather opposite ends of a single dimension (e.g., Kagitcibasi, 1987; Oyserman, 1993; Triandis, Bontempo, Villareal, Asai, \& Lucca, 1988). In this regard, Triandis (e.g., Triandis, 1989; Triandis et al., 1988) argues that both interpretations may be accurate, depending on the scope of the research. That is, a unidimensional structure would be more appropriate if a study integrates a broad range of values, whereas a multidimensional structure may be more fitting for a study with a more restricted focus. Given the broader scope of the present research, we decided to treat individualism and collectivism as unidimensional construct by computing a difference score based on horizontal and vertical individualism and collectivism, respectively (see Holland, Roeder, van Baaren, Brandt, \& Hannover, 2004; Jonas et al., 2009; Pöhlmann, Carranza, Hannover, \& Iyengar, 2007). This approach was also used in previous research investigating ostracism and self-construal (Pfundmair et al., 2015).

2 Breaking down this non-significant interaction revealed that highly interdependent participants did not differ between ostracism and inclusion when not supported by "Pleo," $b=0.06$, $\mathrm{SE}=.53, t(60)=0.12, p=.907$, but indicated more anger when supported by "Pleo," $b=-0.95 \mathrm{SE}=.51, t(60)=-1.86, p=.067$.

\section{References}

Baumeister, R. F., \& Leary, M. R. (1995). The need to belong: Desire for interpersonal attachments as a fundamental human motivation. Psychological Bulletin, 117, 497-529. doi:10.1037/00332909.117.3.497

Derrick, J. L., Gabriel, S., \& Hugenberg, K. (2009). Social surrogacy: How favored television programs provide the experience of belonging. Journal of Experimental Social Psychology, 45, 352-362. doi:10.1016/j.jesp.2008.12.003

Eisenberger, N. I., Lieberman, M. D., \& Williams, K. D. (2003). Does exclusion hurt? An fMRI study of social exclusion. Science, 302, 290-292.

Epley, N., Waytz, A., Akalis, S., \& Cacioppo, J. T. (2008). When we need a human: Motivational determinants of anthropomorphism. Social Cognition, 26, 143-155. doi:10.1521/soco.2008.26. 2.143 
Epley, N., Waytz, A., \& Cacioppo, J. T. (2007). On seeing human: A three-factor theory of anthropomorphism. Psychological Review, 114, 864-886. doi:10.1037/0033-295X.114.4.864

Gardner, W. L., Knowles, M. L., Jefferis, V., Never alone: The interdependent self as a buffer of social exclusion. Manuscript in preparation.

Gardner, W. L., Pickett, C. L., \& Knowles, M. (2005). Social snacking and shielding: Using social symbols, selves, and surrogates in the service of belonging needs. In K. D. Williams, J. P. Forgas, \& W. von Hippel (Eds.), The social outcast: Ostracism, social exclusion, rejection, and bullying (pp. 227-241). New York: Psychology Press.

Gerber, J., \& Wheeler, L. (2009). On being rejected: A meta-analysis of experimental research on rejection. Perspectives on Psychological Science, 4, 468-488. doi:10.1111/j.1745-6924.2009. 01158.x

Gruter, M., \& Masters, R. D. (1986). Ostracism as a social and biological phenomenon: An introduction. Ethnology and Sociobiology, 7, 149-158. doi:10.1016/0162-3095(86)90043-9

Hartgerink, C., van Beest, C., Wicherts, J., \& Williams, K. D. (2015). Manuscript submitted for publication. Ordinal effects of ostracism: A meta-analysis of Cyberball studies.

Hayes, A. F. (2013). Introduction to mediation, moderation, and conditional process analysis: A regression-based approach. New York, NY: Guilford Press.

Heine, S. J., Lehman, D. R., Markus, H. R., \& Kitayama, S. (1999). Is there a universal need for positive self-regard? Psychological Review, 106, 766-794. doi:10.1037/0033-295X.106.4.766

Hofstede, G. H. (1980). Culture's consequences. International differences in work-related values. Beverly Hills, CA: Sage.

Holland, R. W., Roeder, U. -R., van Baaren, R. B., Brandt, A. C., \& Hannover, B. (2004). Don't stand so close to me: the effects of self-construal on interpersonal closeness. Psychological Science, 15, 237-242. doi:10.1111/j.0956-7976.2004.00658.x

Jonas, E., Graupmann, V., Kayser, D. N., Zanna, M., Traut-Mattausch, E., \& Frey, D. (2009). Culture, self, and the emergence of reactance: Is there a "universal freedom? Journal of Experimental Social Psychology, 45, 1068-1080. doi:10.1016/j.jesp.2009.06.005

Kagitcibasi, C. (1987). Individual and group loyalties: Are they compatible. In C. Kagitcibasi (Ed.), Growth and progress in cross-cultural psychology (pp. 94-103). Lisse: Swets \& Zeitlinger.

Knowles, M., Liu, C., \& Sassaman, M. (2015). Meet my friend, chlorophyllis: Evidence that houseplants can serve as social surrogates. In Poster presented at the 16th Annual Convention of the Society for Personality and Social Psychology, Long Beach, CA.

McConnell, A. R., Brown, C. M., Shoda, T. M., Stayton, L. E., \& Martin, C. E. (2011). Friends with benefits: on the positive consequences of pet ownership. Journal of Personality and Social Psychology, 101, 1239-1252. doi:10.1037/a0024506

Oyserman, D. (1993). The lens of personhood: Viewing the self and others in a multicultural society. Journal of Personality and Social Psychology, 65, 993-1009. doi:10.1037/0022-3514.65.5.993

Pfundmair, M., Graupmann, V., Frey, D., \& Aydin, N. (2015). The different behavioral intentions of collectivists and individualists in response to social exclusion. Personality and Social Psychology Bulletin, 41, 363-378. doi:10.1177/0146167214566186

Pöhlmann, C., Carranza, E., Hannover, B., \& Iyengar, S. S. (2007). Repercussions of self-construal for self-relevant and other-relevant choice. Social Cognition, 25, 284-305.

Ren, D., Wesselmann, E. D., \& Williams, K. D. (2013). Interdependent self-construal moderates coping with (but not the initial pain of) ostracism. Asian Journal of Social Psychology, 16, 320-326. doi:10.1111/ajsp.12037

Singelis, T. M., Triandis, H. C., Bhawuk, D., \& Gelfand, M. (1995). Horizontal and vertical dimensions of individualism and collectivism: A theoretical and measurement refinement. Journal of Cross-Cultural Research, 29, 240-275. doi:10.1177/106939719502900302

Triandis, H. C. (1989). The self and social behavior in differing cultural contexts. Psychological Review, 96, 506-520. doi:10.1037/0033-295X.96.3.506

Triandis, H. C., Bontempo, R., Villareal, M. J., Asai, M., \& Lucca, N. (1988). Individualism and collectivism: Cross-cultural perspectives on self-ingroup relationships. Journal of Personality and Social Psychology, 54, 323-338. doi:10.1037/0022-3514.54.2.323

Troisi, J. D., \& Gabriel, S. (2011). Chicken soup really is good for the soul: "comfort food" fulfills the need to belong. Psychological Science, 22, 747-753. doi:10.1177/0956797611407931

Valenti, J., Gabriel, S., \& Young, A. (2012). MayPoster presented at the 84th Annual Meeting of the Midwestern Psychological Association, Chicago, IL. Enrolling at Hogwarts: Social surrogate use and the collective self. 
Watson, D., Clark, L. A., \& Tellegen, A. (1988). Development and validation of brief measures of positive and negative affect: The PANAS scales. Journal of Personality and Social Psychology, 54, 1063-1070. doi:10.1037/0022-3514.54.6.1063

Watson, D., Wiese, D., Vaidya, J., \& Tellegen, A. (1999). The two general activation systems of affect: Structural findings, evolutionary considerations, and psychobiological evidence. Journal of Personality and Social Psychology, 76, 820-838. doi:10.1037/0022-3514.76.5.820

Wesselmann, E. D., Ren, D., Swim, E., \& Williams, K. D. (2013). Rumination hinders recovery from ostracism. International Journal of Developmental Science, 7, 33-39.

Williams, K. D. (2009). Ostracism: A temporal need-threat model. In M. Zanna (Ed.), Advances in Experimental Social Psychology (pp. 279-314). NY: Academic Press.

Williams, K. D., \& Jarvis, B. (2006). Cyberball: A program for use in research on interpersonal ostracism and acceptance. Behavior Research Methods, 38, 174-180. doi:10.3758/BF03192765

Zadro, L., Williams, K. D., \& Richardson, R. (2004). How low can you go? Ostracism by a computer is sufficient to lower self-reported levels of belonging, control, self-esteem, and meaningful existence. Journal of Experimental Social Psychology, 40, 560-567. doi:10.1016/j.jesp.2003. 11.006 